\title{
Fitossociologia e distribuição de espécies arbóreas em uma floresta ribeirinha secundária no Município de Rio Claro, SP, Brasil ${ }^{1}$
}

\author{
EDUARDO MAGALHÃES BORGES PRATA², SÉRGIO DOS ANJOS FERREIRA PINTO³ e \\ MARCO ANTONIO ASSIS 2,4
}

(recebido: 20 de maio de 2009; aceito: 24 de fevereiro de 2011)

\begin{abstract}
Phytosociology and tree species distribution in a secondary riverine forest in the municipality of Rio Claro, SP, Brazil). The floristic and phytosociological structure of a secondary riverine forest situated on a micro-basin area of the Ribeirão Claro river (Rio Claro, SP), was characterized in order to investigate the structure and species distribution in a community with high canopy cover and soil water regime heterogeneity. All tree individuals with perimeter at breast high (PAP) $\geq 10 \mathrm{~cm}$ were sampled in 44 plots of $10 \times 10 \mathrm{~m}$. The water regime was evaluated for a year and the canopy cover was measured with spherical densiometer. Phytosociological descriptors were calculated for the entire sample area and for each group resulted from the ordination and clustering analysis (DCA and Cluster). Low floristic richness (22 species) were found and high importance values were concentrated in a few species. In a local scale, the area presented three distinct micro-environments in relation to the composition and structure of the tree community. The most abundant species distribution was associated to spatial light variation within the forest, due to canopy openness (gaps), and soil water regimes, characterized by different drainage and flooding conditions in the plots during the year.
\end{abstract}

Key words - canopy openness, drainage patterns, riparian forest, swamp forest, tree diversity

RESUMO - (Fitossociologia e distribuição de espécies arbóreas em uma floresta ribeirinha secundária no Município de Rio Claro, SP, Brasil). Foram realizados os levantamentos florístico e fitossociológico em 0,44 hectare de floresta ribeirinha secundária em uma área de micro-bacia do Ribeirão Claro (Rio Claro, SP), visando investigar a estrutura e distribuição das espécies em uma comunidade com elevada heterogeneidade observada para a cobertura de dossel e regime hídrico dos solos. Foram amostrados todos os indivíduos arbóreos com perímetro a altura do peito (PAP) $\geq 10 \mathrm{~cm}$ em 44 parcelas de $10 \times 10 \mathrm{~m}$. O regime hídrico foi avaliado por um ano e a cobertura de dossel foi quantificada com densiômetro esférico. Foram gerados os descritores fitossociológicos para toda a área amostral e para cada grupo resultante das análises de ordenação (DCA) e de agrupamento (Cluster). Verificou-se baixa riqueza florística (22 espécies) e elevados valores de importância concentrados em poucas espécies. A área apresentou, em escala local, três micro-ambientes distintos em relação à composição e estrutura da comunidade arbórea. A distribuição das espécies mais abundantes esteve associada à variação espacial da luminosidade no interior da mata, decorrente de aberturas no dossel (clareiras), e ao regime hídrico dos solos, caracterizado por diferentes condições de drenagem e alagamento nas parcelas ao longo do ano.

Palavras-chave - cobertura de dossel, diversidade arbórea, floresta ripária, mata de brejo, padrões de drenagem

\section{Introdução}

As florestas tropicais que margeiam cursos d'água, definidas também como florestas ribeirinhas, dentre outras denominações (Rodrigues 2000), podem apresentar características florísticas associadas ao regime hídrico, às condições topográficas, edáficas e microclimáticas locais, dentre outros fatores (Oliveira Filho et al. 1994, Durigan et al. 2000, Rodrigues \& Nave 2000).

1. Parte da monografia de graduação do primeiro autor, Curso de Ciências Biológicas, Universidade Estadual Paulista - Unesp, Rio Claro, SP, Brasil.

2. Universidade Estadual Paulista - Unesp, Instituto de Biociências, Departamento de Botânica, Caixa Postal 199, 13506-900 Rio Claro, SP, Brasil.

3. Universidade Estadual Paulista - Unesp, Instituto de Geociências e Ciências Exatas, Centro de Análise e Planejamento Ambiental, 13506-900 Rio Claro, SP, Brasil.

4. Autor para correspondência: massis@rc.unesp.br
Os eventos periódicos de inundação fluvial alteram as propriedades físico-químicas dos solos através da ação de processos erosivos ou de sedimentação de partículas minerais, matéria orgânica e nutrientes, além de os tornarem pouco oxigenados, devido à saturação hídrica (Ab'Saber 2000, Ferreira \& Ribeiro 2001). Outro fator importante na dinâmica destas florestas é a formação de clareiras, decorrentes principalmente da queda de árvores ou galhos. A maior entrada de luz no interior da floresta proporcionada por aberturas no dossel altera as condições microclimáticas locais, afetando de diferentes maneiras o desenvolvimento das espécies (Denslow 1980, Brokaw 1982, Whitmore 1989, Gandolfi et al. 1995, Souza \& Martins 2005, Gandolfi et al. 2007).

Estudos florísticos e fitossociológicos das vegetações ribeirinhas têm revelado informações importantes no sentido de explicar a distribuição das espécies nestas comunidades (Oliveira Filho et al. 1994, van den Berg \& 
Oliveira Filho 2000, Souza et al. 2003, Damasceno-Júnior et al. 2005, Silva et al. 2007, Teixeira et al. 2008). Poucos estudos, no entanto, analisaram a composição e a estrutura em áreas de formação ribeirinha secundária, geralmente presentes na forma de fragmentos em diferentes estágios de sucessão, como no caso do Estado de São Paulo. As extensas áreas ribeirinhas definidas como APPs - Áreas de Preservação Permanente, de acordo com a Lei 4.771 de 15 de setembro de 1965 (Milaré 1991), podem apresentar diferentes potenciais para regeneração, dependendo principalmente da distância em relação a outros remanescentes e da dinâmica ecológica local, o que reforça ainda mais a necessidade de estudos nestas comunidades.

No presente estudo, foram realizados os levantamentos florístico-fitossociológico num fragmento de floresta ribeirinha em regeneração e das variáveis ambientais 'regime hídrico'e 'cobertura de dossel' para responder às seguintes questões: 1) Em uma pequena escala espacial de análise, é possível detectar variações florísticas e estruturais na comunidade? Se a composição de espécies estiver respondendo a um ou mais gradientes ambientais, esperamos encontrar grupos de maior ou menor afinidade florística na área de estudo; 2) Neste caso, os grupos detectados poderiam ser explicados pelas variáveis ambientais avaliadas? Acreditamos que os efeitos da inundação sobre a distribuição de espécies arbóreas em florestas ribeirinhas (como já demonstrado por outros autores para áreas de floresta primária) também podem afetar a composição em áreas de sucessão secundária, a partir da seleção de espécies tolerantes ao alagamento, enquanto a condição de maior luminosidade favoreceria principalmente espécies mais generalistas de início de sucessão.

\section{Material e métodos}

Área de estudo - O presente trabalho foi desenvolvido em um trecho de floresta ribeirinha em regeneração há pelo menos quarenta anos. A partir de observações prévias em campo, foi constatada a ocorrência de áreas aparentemente distintas quanto ao regime hídrico dos solos, isto é, sob influência de inundações ou não. Também foram observadas variações na cobertura de dossel da vegetação, devido à presença de clareiras e bordas. A floresta estudada localiza-se entre o câmpus da Universidade Estadual Paulista-Unesp e a Floresta Estadual Edmundo Navarro de Andrade-Feena, nas coordenadas $22^{\circ} 23^{\prime} 35^{\prime \prime}$ - $22^{\circ} 23^{\prime} 40^{\prime \prime} \mathrm{S}$ e

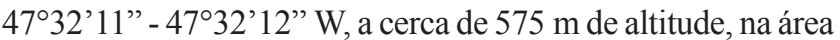
de confluência do Córrego do Jardim Bandeirantes no Ribeirão Claro, Município de Rio Claro, SP.

O clima da região é do tipo Cwa na classificação zonal de Köppen (1948), caracterizado como tropical, com estação chuvosa (ocorrendo dominantemente) de outubro a março e estação seca de abril a setembro. A precipitação média anual é de $1.482 \mathrm{~mm}$. As temperaturas máximas e mínimas atingem em média $24,9^{\circ} \mathrm{C}$ no mês mais quente e $17,2^{\circ} \mathrm{C}$ no mês mais frio, conforme dados da estação meteorológica do Centro de Análise e Planejamento Ambiental (Ceapla) da Unesp - Rio Claro, para o período de 1994 a 2004.

A paisagem local é caracterizada por um quadro geológico-geomorfológico constituído por maciços e morrotes suportados por rochas eruptivas básicas, colinas amplas e dissecadas, planícies aluvionares de inundação e depósitos de assoreamento, desenvolvidos sobre litologias da formação Corumbataí e Rio Claro (Souza 2000, Pires 2003). Particularmente, na área de estudo, ocorrem solos aluviais hidromórficos e orgânicos e a drenagem apresenta escoamento fluvial anastomosado, formado por canais estreitos, perenes ou intermitentes, conforme as alternâncias de vazante e cheia (dezembro a março) (S.A.F. Pinto, dados não publicados).

A vegetação original da região era composta de manchas de floresta estacional semidecidual, formações florestais ribeirinhas e diferentes fisionomias de Cerrado. Atualmente ainda existem alguns poucos fragmentos representativos destas formações vegetais na região de Rio Claro.

A área estudada faz parte de uma mancha de floresta estacional semidecidual ribeirinha com influência fluvial (sensu Rodrigues 2000), em regeneração há pelo menos quatro décadas e ainda com interferência antrópica, como abertura de trilhas e presença de gado nas bordas. Pode-se observar, a partir de fotografias aéreas do local, que até o ano de 1962 a vegetação apresentava fisionomia predominantemente herbáceo-arbustiva. É provável que em um período anterior a este tenha havido plantio e corte de espécies de Eucalyptus pela antiga Companhia Paulista de Estradas de Ferro (território atualmente da Feena), visto que atualmente existem algumas árvores destas espécies isoladas em trechos da borda da mata.

Coleta e análise de dados - O levantamento florístico e fitossociológico foi realizado utilizando o método de parcelas (Müller-Dombois \& Ellenberg 1974). Foram instaladas 44 parcelas contíguas de $100 \mathrm{~m}^{2}(10 \times 10 \mathrm{~m})$, totalizando uma área amostral de 0,44 ha, na margem esquerda do Ribeirão Claro. A distribuição das parcelas se deu em função da rede de drenagem local, abrangendo trechos sujeitos à inundação fluvial, à jusante do ponto de confluência do Córrego do Jardim Bandeirantes no Ribeirão Claro e trechos livres de alagamento, à montante da confluência.

Foram amostrados todos os indivíduos arbóreos com perímetro a 1,3 $\mathrm{m}$ da superfície do solo (perímetro a altura do peito - PAP) $\geq 10 \mathrm{~cm}$. Cada planta recebeu uma plaqueta de alumínio numerada, teve seu PAP registrado, altura estimada e um ramo coletado (preferencialmente reprodutivo). A identificação taxonômica se deu por meio de chaves de identificação, ajuda de especialistas e comparação com materiais do Herbário Rioclarense (HRCB), onde as exsicatas dos materiais que estavam reprodutivos foram incorporadas, e se baseou no sistema proposto em APG II (2003), segundo adaptação de Souza \& Lorenzi (2005). 
Para descrever a estrutura da comunidade arbórea foram calculados os descritores fitossociológicos: densidade, frequência e dominância absolutas e relativas e valor de importância (VI), além do índice de diversidade de Shannon \& Weaver $\left(H^{\prime}\right)$ e equabilidade de Pielou $\left(J^{\prime}\right)$ (Brower \& Zar 1984). Os cálculos foram realizados no programa FITOPAC (Shepherd 1995).

As relações de similaridade florística entre parcelas foram investigadas através de uma Análise de Correspondência Destendenciada - DCA (McCune \& Grace 2002), a partir de uma matriz de abundância de espécies por parcela, considerando todas as espécies ocorrentes com mais de 10 indivíduos. Foi realizada uma Análise de Agrupamento - Cluster (McCune \& Grace 2002) utilizando o índice de Bray-Curtis com o objetivo de auxiliar a interpretação da DCA. Estas duas análises foram realizadas no software PCORD versão 4.0 (McCune \& Mefford 1999).

As condições de umidade do solo foram mensalmente avaliadas em todas as parcelas, no período de abril de 2004 a março de 2005. Os registros foram conduzidos conforme indicado em Teixeira et al. (2008), com adaptações, considerando três categorias qualitativas: (a) solo seco (ausência de saturação); (b) solo saturado superficialmente (encharcado); (c) solo inundado (sob lâmina d'água). Em campo, cada parcela de $10 \times 10 \mathrm{~m}$ foi subdividida em quatro sub-parcelas de $5 \times 5 \mathrm{~m}$, sendo atribuído a cada uma delas uma das categorias de solo no momento da avaliação. Os valores foram transformados em frequência de ocorrência de cada tipo de condição (ao longo de doze meses) para cada parcela.

A cobertura de dossel nas parcelas foi estimada com densiômetro esférico (Lemmon 1957). Os registros foram obtidos em abril de 2004 e as medições foram realizadas em sub-parcelas de $5 \times 5 \mathrm{~m}$ (quatro por parcela). Os procedimentos para leitura e cálculo da abertura de dossel foram os mesmos descritos em Souza \& Martins (2005). Foi gerado um mapa de cobertura da área em um Sistema de Informações Geográficas (ArcGIS 9.1 ESRI), considerando quatro classes de porcentagem, a partir dos valores de mínima e máxima abertura encontrados.

\section{Resultados}

Florística e fitossociologia - Foi encontrado um total de 1.697 indivíduos vivos, distribuídos em 22 espécies e 13 famílias (tabela 1). A densidade total de plantas foi de 3.857 ind ha-1, que somaram uma área basal de

Tabela 1. Famílias e espécies arbóreas (PAP $\geq 10 \mathrm{~cm}$ ) encontradas na floresta ribeirinha secundária da região de confluência do Córrego do Jardim Bandeirantes no Ribeirão Claro, Município de Rio Claro, SP. Testemunho: n⿳o do HRCB ou do coletor E.M.B. Prata.

Table 1. Families and tree species (PAP $\geq 10 \mathrm{~cm}$ ) sampled in a secondary forest in the confluence region of Jardim Bandeirantes stream in Ribeirão Claro river, Rio Claro municipality, SP. Voucher: HRCB number or colector E.M.B. Prata.

\begin{tabular}{|c|c|c|}
\hline Famílias & Espécies & HRCB ou coletor \\
\hline Anacardiaceae & Tapirira guianensis Aubl. & 51231 \\
\hline Combretaceae & Terminalia triflora (Griseb.) Lillo & 51222 \\
\hline \multirow[t]{5}{*}{ Euphorbiaceae } & Alchornea glandulosa Poepp. \& Endl. & Prata 130 \\
\hline & Croton urucurana Baill. & 51294 \\
\hline & Sapium glandulosum (L.) Morong & Prata 141 \\
\hline & Sebastiania brasiliensis Spreng. & 51223 \\
\hline & Sebastiania commersoniana (Baill.) L. B. Sm. \& Downs & 51293 \\
\hline Fabaceae & Inga vera Willd. & 51224 \\
\hline Lauraceae & Nectandra megapotamica (Spreng.) Mez & 51227 \\
\hline Meliaceae & Guarea guidonia (L.) Sleumer & 51225 \\
\hline Myrsinaceae & Rapanea gardneriana (A. DC.) Mez & Prata 133 \\
\hline \multirow[t]{6}{*}{ Myrtaceae } & Blepharocalyx salicifolius (Kunth) O. Berg & 51232 \\
\hline & Eucalyptus citriodora Hook. & Prata 138 \\
\hline & Eugenia moraviana $\mathrm{O}$. Berg & 51220 \\
\hline & Myrcia laruotteana Cambess. & 51233 \\
\hline & Myrciaria tenella (DC.) O. Berg & Prata 132 \\
\hline & Psidium guajava $\mathrm{L}$. & Prata 146 \\
\hline Rubiaceae & Guettarda virbunoides Cham. \& Schltdl. & Prata 139 \\
\hline Salicaceae & Xylosma venosa $\mathrm{N}$. E. Br. & 51295 \\
\hline Sapindaceae & Allophylus edulis Radlk. ex Warm. & Prata 151 \\
\hline Picramniaceae & Picramnia sellowii Planch. & Prata 144 \\
\hline Urticaceae & Cecropia pachystachya Trécul & Prata 157 \\
\hline
\end{tabular}


21,66 $\mathrm{m}^{2} \mathrm{ha}^{-1}$. O índice de diversidade $\left(H^{\prime}\right)$ encontrado foi igual a 1,8 nats indivíduos ${ }^{-1}$ e a equabilidade $\left(J^{\prime}\right)$ igual a 0,584 . A altura média do dossel da mata foi de $7,3 \mathrm{~m}$ (d.p. $=3,03)$, com ocorrrência de indivíduos emergentes que ultrapassaram $15 \mathrm{~m}$ de altura, como é o caso de representantes das espécies Blepharocalyx salicifolius, Croton urucurana, Eucalyptus citriodora, Nectandra megapotamica, Sebastiania brasiliensis. Outras espécies, dentre elas Myrcia laruotteana e Tapirira guianensis, foram representadas predominantemente por indivíduos com alturas variando entre 5,3 e 7,6 m.

As espécies mais abundantes foram Myrcia laruotteana (34,3\% dos indivíduos), Sebastiania brasiliensis (21,9\%), Croton urucurana (15,2\%) e Sebastiania commersoniana (13\%), totalizando $85 \%$ dos indivíduos amostrados e perfazendo $72,6 \%$ do valor de importância (VI). Terminalia triflora, Myrciaria tenella, Allophylus edulis, Alchornea glandulosa, Rapanea gardneriana e Psidium guajava (27\% do total de espécies) apresentaram apenas um indivíduo e os menores VI da comunidade (tabela 2).

As famílias Myrtaceae (seis espécies) e Euphorbiaceae (cinco espécies) somaram 79\% do VI total, enquanto as demais foram representadas por apenas uma espécie. Combretaceae, Sapindaceae e Myrsinaceae foram representadas por somente um indivíduo e apresentaram os menores valores de importância.

Análises multivariadas - A análise de correspondência destendenciada (DCA) distinguiu três grupos de parcelas (figura 1). O primeiro grupo, localizado na parte esquerda mediano-inferior no gráfico (grupo 1, parcelas 1-8, 10-21 e 23), está associado principalmente à abundância relativa das espécies Sebastiania brasiliensis e $S$. commersoniana. O grupo 2, na parte direita inferior do gráfico (parcelas 28, 33-35 e 37-43), caracterizou-se pela abundância relativa de Nectandra megapotamica, Croton urucurana e Blepharocalyx salicifolius. A

Tabela 2. Parâmetros fitossociológicos da comunidade arbórea $(\mathrm{PAP} \geq 10 \mathrm{~cm})$ amostrada na região de confluência do Córrego do Jardim Bandeirantes no Ribeirão Claro, Município de Rio Claro, SP. (NI = número de indivíduos; DoR = Dominância Relativa; FR = Frequência Relativa; VI = Valor de Importância; Hma = Altura máxima; Hme = Altura média; Dma = Diâmetro máximo; Dme = Diâmetro médio).

Table 2. Phytosociological parameters of the tree community $(\mathrm{PAP} \geq 10 \mathrm{~cm}$ ) sampled in the confluence region of the Jardim Bandeirantes stream in Ribeirão Claro river, Rio Claro municipality, SP. $(\mathrm{NI}=$ number of individuals; DoR $=$ Relative Dominance; FR = Relative frequency; VI = Importance Value; Hma = Maximum height; Hme = Average height; Dma = Maximum diameter; Dme $=$ Average diameter) .

\begin{tabular}{lrrrrrrrr}
\hline Espécies & NI & DoR & FR & VI & Hma & Hme & Dma & Dme \\
\hline Croton urucurana & 259 & 33,13 & 18,43 & 66,82 & 18 & 8,9 & 31,8 & 11,4 \\
Myrcia laruotteana & 582 & 9,54 & 15,21 & 59,02 & 10 & 5,3 & 16,6 & 4,3 \\
Sebastiania brasiliensis & 373 & 18,00 & 10,60 & 50,61 & 17 & 8,0 & 17,3 & 7,2 \\
Sebastiania commersoniana & 221 & 16,00 & 12,44 & 41,46 & 14 & 8,0 & 20,7 & 8,6 \\
Blepharocalyx salicifolius & 98 & 8,31 & 9,68 & 23,75 & 22 & 8,6 & 29,3 & 9,0 \\
Nectandra megapotamica & 86 & 5,96 & 11,98 & 23,00 & 17 & 7,9 & 24,6 & 7,9 \\
Inga vera & 17 & 3,55 & 3,69 & 8,24 & 15 & 9,3 & 28,7 & 13,6 \\
Tapirira guianensis & 29 & 0,89 & 4,61 & 7,21 & 13 & 7,6 & 10,5 & 5,7 \\
Eucalyptus citriodora & 8 & 3,56 & 2,76 & 6,80 & 25 & 19,1 & 33,5 & 22,3 \\
Sapium glandulosum & 5 & 0,15 & 2,30 & 2,75 & 8 & 5,8 & 8,4 & 5,8 \\
Xylosma venosa & 4 & 0,27 & 1,38 & 1,89 & 12 & 7,6 & 12,4 & 8,4 \\
Cecropia pachystachya & 2 & 0,18 & 0,92 & 1,22 & 8 & 7,3 & 11,7 & 10,3 \\
Eugenia moraviana & 2 & 0,04 & 0,92 & 1,08 & 7 & 5,5 & 5,1 & 4,7 \\
Picramnia sellowii & 2 & 0,03 & 0,92 & 1,07 & 5,5 & 5,0 & 4,8 & 4,0 \\
Guarea guidonia & 2 & 0,02 & 0,92 & 1,06 & 5 & 4,5 & 3,7 & 3,4 \\
Terminalia triflora & 1 & 0,15 & 0,46 & 0,67 & 12 & 12,0 & 13,5 & 13,5 \\
Guettarda virbunoides & 2 & 0,09 & 0,46 & 0,67 & 8 & 7,3 & 7,5 & 7,3 \\
Alchornea glandulosa & 1 & 0,05 & 0,46 & 0,57 & 6 & 6,0 & 8,0 & 8,0 \\
Allophylus edulis & 1 & 0,02 & 0,46 & 0,54 & 7 & 7,0 & 4,8 & 4,8 \\
Myrciaria tenella & 1 & 0,01 & 0,46 & 0,53 & 4,5 & 4,5 & 3,8 & 3,8 \\
Psidium guajava & 1 & 0,01 & 0,46 & 0,53 & 3,5 & 3,5 & 3,2 & 3,2 \\
Rapanea gardneriana & 1 & 0,01 & 0,46 & 0,53 & 4,5 & 4,5 & 3,2 & 3,2 \\
\hline
\end{tabular}




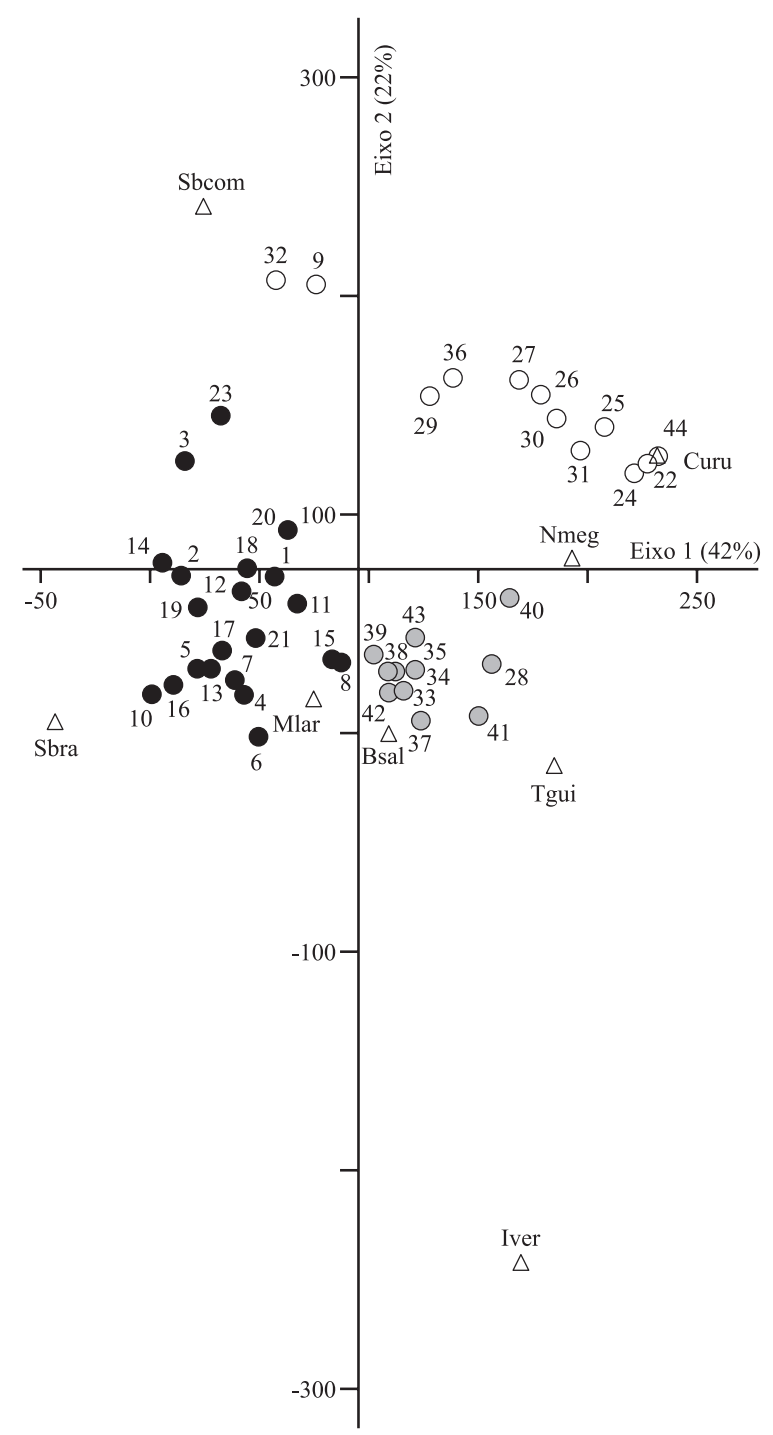

Figura 1. Análise de correspondência destendenciada (DCA) aplicada a partir de uma matriz de abundância por espécie nas 44 parcelas amostrais, localizadas na região de confluência do Córrego do Jardim Bandeirantes no Ribeirão Claro, Município de Rio Claro, SP. $(\bullet=$ grupo $1 ; 0=$ grupo 2 ; $\mathrm{O}=$ grupo 3 e $\Delta=$ espécies: Bsal = Blepharocalyx salicifolius; Curu = Croton urucurana $;$ Iver $=$ Inga vera $;$ Mlar $=$ Myrcia laruotteana; Nmeg = Nectandra megapotamica; Sbra $=$ Sebastiania brasiliensis; $\mathrm{Scom}=$ Sebastiania commersoniana e Tgui = Tapirira guianensis) .

Figure 1. Detrended correspondence analysis (DCA) applied from a matrix of abundance per species on 44 sample plots, situated in the confluence region of Jardim Bandeirantes stream in Ribeirão Claro river, Rio Claro municipality, SP. $(\bullet=$ group $1 ; O=$ group $2 ; O=$ group 3 and $\Delta=$ species: Bsal = Blepharocalyx salicifolius; Curu = Croton urucurana; Iver = Inga vera $;$ Mlar = Myrcia laruotteana $;$ Nmeg = Nectandra megapotamica; Sbra = Sebastiania brasiliensis; Scom $=$ Sebastiania commersoniana and Tgui $=$ Tapirira guianensis). espécie Myrcia laruotteana foi abundante nos grupos 1 e 2, contribuindo fortemente para a maior proximidade entre eles no gráfico. O terceiro grupo (parcelas 9, 22, 24-27, 29-32, 36 e 44), localizado principalmente à direita e acima no gráfico, está associado principalmente à abundância relativa de Croton urucurana e Sebastiania commersoniana. Os dois eixos principais explicaram $64 \%$ da variância total (autovalor), representadas no gráfico pelos eixos um e dois $(42 \%$ e $22 \%$ da variância total, respectivamente). A análise de Cluster corroborou os resultados obtidos na DCA (figura 2). Dois grupos se formaram num nível próximo de $15 \%$ de fusão, um deles correspondendo ao grupo 3 da DCA, enquanto o outro subdividiu-se em dois num nível em torno de $32 \%$ de fusão, equivalentes aos grupos 1 e 2 da análise de correspondência. A parcela 40, que foi incluída no grupo 2 na DCA, apareceu totalmente isolada das demais nesta análise.

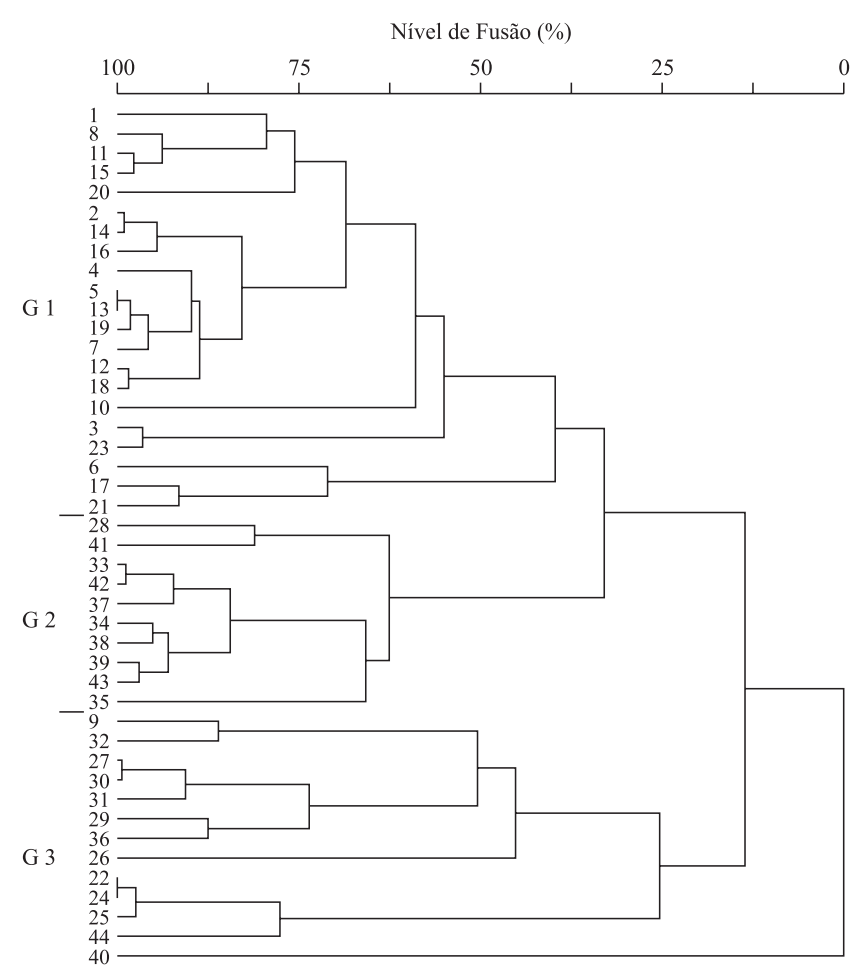

Figura 2. Análise de agrupamento (Cluster) aplicada a partir de uma matriz de abundância por espécie nas 44 parcelas amostrais, localizadas na região de confluência do Córrego do Jardim Bandeirantes no Ribeirão Claro, Município de Rio Claro, SP.

Figure 2. Clustering analysis (Cluster) applied from a matrix of abundance per species on 44 sample plots, situated in the confluence region of Jardim Bandeirantes stream in Ribeirão Claro river, Rio Claro municipality, SP. 
Variáveis ambientais - A distribuição das parcelas que compõem os grupos detectados pela DCA em um mapa hidrográfico da área e a classificação das mesmas em classes de porcentagem de abertura de dossel são apresentadas nas figuras 3 e 4 para melhor visualização das relações entre composição de espécies e variáveis ambientais. Encontramos 15 espécies (sendo três exclusivas) distribuídas em nove famílias nas parcelas do grupo 1. As três espécies de maior densidade (Sebastiania brasiliensis, Myrcia laruotteana e Sebastiania commersoniana) somaram $86,3 \%$ do total de indivíduos. O índice de diversidade $\left(H^{\prime}\right)$ foi de 1,49 e a equabilidade $\left(J^{\prime}\right)$ igual a 0,55 . A

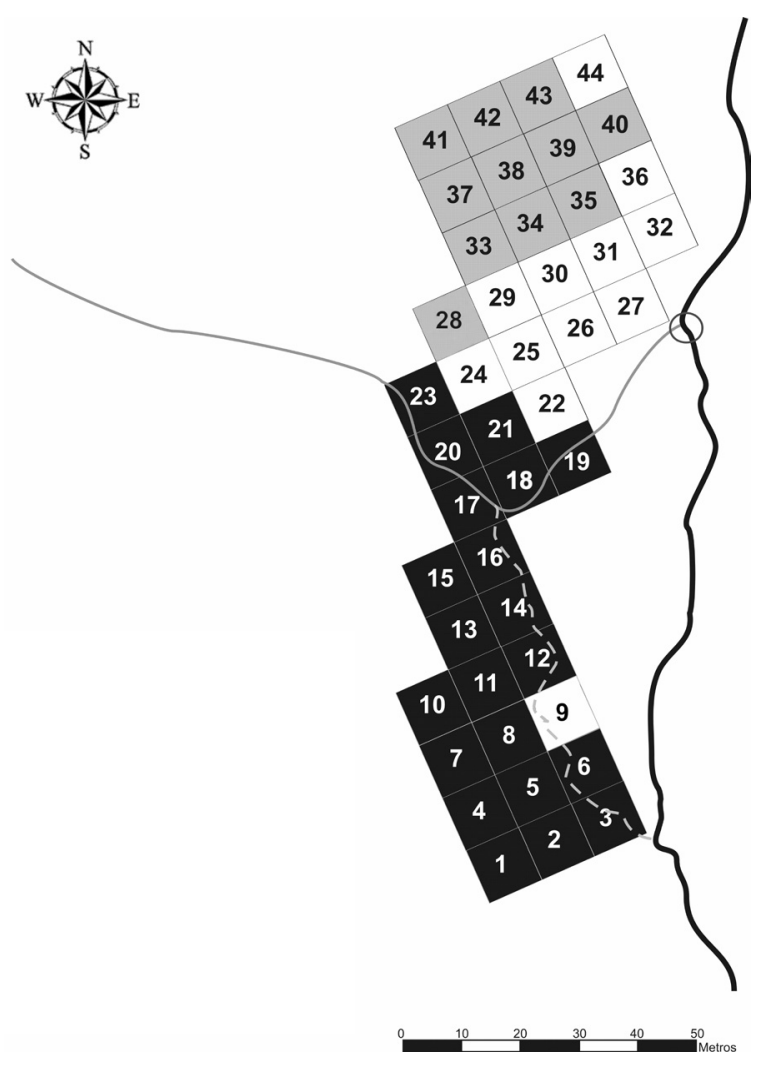

Figura 3. Distribuição espacial das 44 parcelas amostrais (grupos 1, 2 e 3 resultantes da DCA) e esquema da hidrografia local na região de confluência do Córrego do Jardim Bandeirantes no Ribeirão Claro, Município de Rio Claro, SP. $(\mathbf{\square}=1 ; \square=2 ; \square=3 ;-=$ Ribeirão Claro; $-=$ Córrego do Jardim Bandeirantes; - -- = Canal intermitente; $\mathrm{O}=$ Ponto de Confluência.)

Figure 3. Spatial distribution of the 44 sample plots (groups 1,2 and 3 resulted from DCA) and local hydrography at the confluence region of Jardim Bandeirantes stream in Ribeirão Claro river, Rio Claro municipality, SP. $(\square=1 ; \square=2 ; \square=3$; $-=$ Ribeirão Claro; - = Córrego do Jardim Bandeirantes; - - - = Intermittent stream; $\mathrm{O}=$ Local of confluence.) densidade total e a área basal encontradas para o grupo 1 foram estimadas em 4.976 inds ha- e $23,9 \mathrm{~m}^{2} \mathrm{ha}^{-1}$, respectivamente. $\mathrm{O}$ dossel da vegetação apresentou média de abertura de 9,59\%, com variações entre $6,2 \%$ a $16,9 \%$. Neste grupo, as parcelas estiveram susceptíveis a constantes eventos de alagamento dos solos durante inundações causadas pelo Ribeirão Claro e pelo córrego do Jardim Bandeirantes, por um período de pelo menos dois meses (janeiro e fevereiro de 2005). Todas as parcelas apresentaram manchas de saturação hídrica nos solos por períodos que variaram de seis a 12 meses

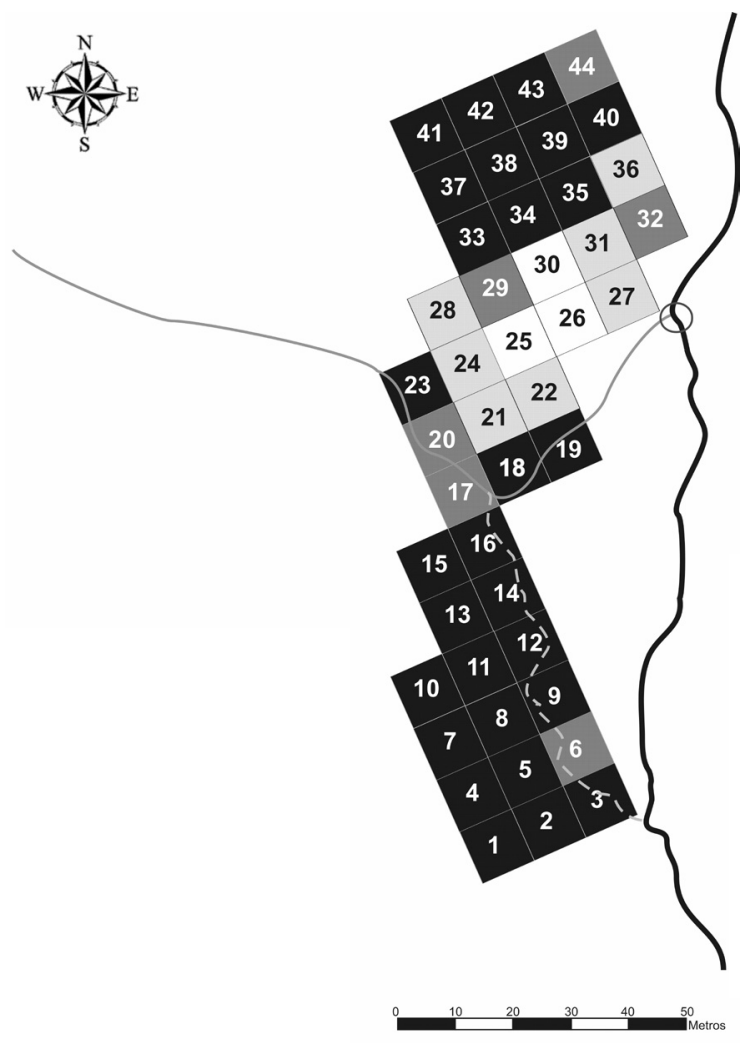

Figura 4. Abertura do dossel avaliada para as 44 parcelas e esquema da hidrografia local na região de confluência do Córrego do Jardim Bandeirantes no Ribeirão Claro, Município de Rio Claro, SP. $(\square=20,57-25,41 ; \square=15,71-20,56$; $\square=10,86-15,70 ; \boldsymbol{\square}=6,00-10,85 ;-=$ Ribeirão Claro; - = Córrego do Jardim Bandeirantes; - - - = Canal intermitente; $\mathrm{O}=$ Ponto de Confluência.)

Figure 4. Canopy opening evaluated for the 44 sample plots and local hydrography at the confluence region of Jardim Bandeirantes stream in Ribeirão Claro river, Rio Claro municipality, SP. ( $\square=20.57-25.41 ; \square=15.71-20.56$; $\square=10.86$ - 15.70; $\boldsymbol{\square}=6.00-10.85 ;-=$ Ribeirão Claro; - = Córrego do Jardim Bandeirantes; - - - = Canal intermitente; $\mathrm{O}=$ Local of confluence.) 
No grupo 2, Myrcia laruotteana, Nectandra megapotamica, Croton urucurana e Blepharocalyx salicifolius somaram $87 \%$ dos indivíduos dentre um total de 17 espécies (quatro exclusivas). $\mathrm{O}$ índice de diversidade $\left(H^{\prime}\right)$ foi de 1,64 e o de equabilidade $\left(J^{\prime}\right)$ igual a 0,58 . Os valores de densidade e área basal total avaliados foram de 4.154 inds ha-1 e $23 \mathrm{~m}^{2} \mathrm{ha}^{-1}$, respectivamente. A porcentagem média de abertura do dossel foi de 8,68 , com variações de $6 \%$ a $17,1 \%$ entre as parcelas. Nas parcelas deste grupo não se observou ocorrência de alagamento durante as cheias fluviais e os solos apresentaram, no geral, manchas de saturação hídrica por períodos de dois a seis meses.

Um total de apenas 10 espécies e quatro famílias foram registradas no grupo 3. As espécies mais abundantes (Croton urucurana e Sebastiania commersoniana) concentraram $89 \%$ dos indivíduos. Os índices de diversidade $\left(H^{\prime}\right)$ e equabilidade $\left(J^{\prime}\right)$ calculados foram de 1,02 e 0,44 , respectivamente, os menores entre os grupos. A densidade de indivíduos foi de 1.625 inds ha $^{-1} \mathrm{e}$ a área basal foi de $15,9 \mathrm{~m}^{2} \mathrm{ha}^{-1}$, constituindo os menores valores quando comparados entre os grupos. A média de abertura do dossel foi de $17,45 \%$, variando entre $6,5 \%$ a $25,4 \%$, em decorrência da clareira em regeneração presente nas parcelas deste grupo. O regime hídrico dos solos caracterizou-se pela ocorrência de alagamentos pouco frequentes dentro de um período de um mês (exceção da parcela nove e 32 , onde os alagamentos perduraram por pelo menos dois meses) e pela presença de manchas de saturação hídrica por períodos de dois a quatro meses, no máximo. As parcelas nove e 32 aparecem relativamente isoladas no gráfico da DCA, caracterizadas pela alta densidade relativa de Sebastiania commersoniana, menor densidade de Croton urucurana e ausência de Sebastiania brasiliensis.

\section{Discussão}

A riqueza florística observada para a mata estudada (22 espécies) é muito baixa em comparação com valores encontrados para outras áreas ribeirinhas do Estado de São Paulo (e.g. Gibbs \& Leitão Filho 1978, Ivanauskas et al. 1997, Bernacci et al. 1998, Teixeira et al. 2008), que no geral ocorreram com mais de 35 espécies. É importante salientar que apesar de haver diferenças metodológicas (tamanho de área amostral e critério de inclusão) entre os estudos, as comparações oferecem uma idéia aproximada da discrepância em termos de riqueza florística entre esta e as demais áreas consideradas.
Em uma escala reduzida de análise, variações florísticas e estruturais puderam ser detectadas na comunidade. A ocorrência de associação entre parcelas e espécies na análise de correspondência (DCA) indicou de maneira indireta a influência de uma ou mais variáveis sobre a distribuição de algumas espécies na comunidade. Os grupos resultantes desta análise também apresentaram variações em relação à densidade total de indivíduos, à área basal e à diversidade de espécies.

Variações na composição e densidade de algumas espécies nas parcelas podem estar associadas ao regime hídrico dos solos e à luminosidade no interior da floresta. As inundações fluviais levaram os solos à submersão total em mais de metade das parcelas. Manchas de saturação hídrica também foram observadas nas parcelas por diferentes períodos. O encharcamento dos solos esteve associado à presença quase constante de canais estreitos, rasos e de baixa energia (lentos) provenientes do Córrego do Jardim Bandeirantes e de afloramentos do lençol freático em área adjacente, que formam uma rede difusa pelas parcelas. Segundo Lobo \& Joly (2000) e Ferreira \& Ribeiro (2001), o excesso de água e a restrição ao oxigênio limitam o desenvolvimento de muitas espécies de plantas, inibindo a germinação de sementes e/ou o crescimento de plântulas. Nessas condições, o ar presente nos poros do solo é substituído pela água, dificultando as trocas gasosas com a atmosfera (Ferreira \& Ribeiro 2001). Algumas espécies possuem mecanismos adaptativos para suportar os períodos de inundação (MazzoniViveiros \& Luchi 1989), como a utilização de rotas de difusão do oxigênio da parte aérea para a raiz da planta ou mesmo o desenvolvimento de metabolismo anaeróbico (Joly 1986).

Áreas de solos inundáveis em florestas ribeirinhas podem apresentar alta densidade de uma ou poucas espécies (Budke et al. 2008). Neste estudo, as espécies Sebastiania commersoniana e $S$. brasiliensis estiveram restritas às áreas alagáveis, com elevados valores de densidade e dominância. A ocorrência de S. brasiliensis em florestas inundáveis da região Sudeste, geralmente em alta frequência, foi relatada por Silva et al. (2007). A tolerância de $S$. commersoniana ao alagamento (Lobo \& Joly 2000) foi associada, por Kolb et al. (1998), a modificações morfoanatômicas e metabólicas que a espécie apresenta durante períodos de alagamento. Segundo estes autores, após períodos de inundação de até 60 dias, pelo menos, os indivíduos podem retomar o crescimento, o que explica, em parte, o fato da espécie geralmente ser uma das dominantes em áreas de alagamentos periódicos, como neste caso. Por outro 
lado, as espécies adaptadas ao alagamento podem apresentar baixa capacidade competitiva em áreas de solos bem drenados (Lobo \& Joly 2000), o que talvez explique a ausência de Sebastiania commersoniana e $S$. brasiliensis nas parcelas de solos secos e livres de inundação.

Outras espécies apresentaram caráter mais generalista em relação ao regime hídrico. Myrcia laruotteana, por exemplo, foi a espécie mais abundante nas áreas alagáveis e segunda mais abundante nas áreas não alagáveis, mas ocorreu com apenas dois indivíduos na área de clareira. Essa evidência sugere que a condição de maior luminosidade e/ou a competição com espécies colonizadoras de clareiras tenham inibido o estabelecimento de $M$. laruotteana nas parcelas deste grupo, onde Croton urucurana se destacou em termos de densidade e dominância. $\mathrm{O}$ aumento da luminosidade e as transformações microclimáticas decorrentes da formação de clareiras (Denslow 1980, Whitmore 1989) podem ter favorecido o crescimento populacional de C. urucurana em alta densidade, uma vez que a espécie apresenta elevado potencial de colonização em ambientes ribeirinhos perturbados (Assad-Ludewigs et al. 1989).

As variações florísticas e estruturais observadas refletem a heterogeneidade ambiental do trecho analisado, geralmente característica das florestas ribeirinhas (Rodrigues \& Nave 2000), com presença de micro-ambientes mais ou menos favoráveis ao desenvolvimento de determinadas espécies. É provável que na área de estudo o alagamento do solo em algumas parcelas tenha criado um ambiente mais seletivo, em contraposição ao grupo de parcelas livre de inundação, que apresentou os maiores valores de riqueza e diversidade. Geralmente baixos valores de riqueza e diversidade local são encontrados em áreas de solos encharcados (Cattanio et al. 2002, Silva et al. 2007, Budke et al. 2008, Teixeira et al. 2008). Em contrapartida, a ocorrência de espécies restritas a estes ambientes pode contribuir para o aumento da diversidade de espécies em uma escala regional de análise (Teixeira et al. 2008).

Aos baixos valores de riqueza e diversidade encontrados para a área podemos atribuir, em última análise, o tempo de regeneração da mata, a ocorrência de processos de perturbação de origem antrópica e de distúrbios naturais ocasionados, principalmente, pelos eventos de inundação fluvial. Segundo Capon \& Brock (2006), os processos de sucessão geralmente são mais lentos em ambientes suscetíveis ao alagamento. A velocidade de regeneração em florestas neotropicais depende ainda da conectividade dos fragmentos florestais na paisagem, que podem atuar como fontes dispersoras de sementes e propágulos (Guariguata \& Ostertag 2002). No presente contexto, a paisagem local é pobre em remanescentes florestais, a exemplo das paisagens que atualmente compõem grandes extensões do território do Estado de São Paulo.

Os resultados apresentados confirmam a existência de variações florísticas e estruturais em áreas de sucessão secundária mesmo numa pequena escala, que se devem às variáveis ambientais (umidade do solo e luminosidade) e seletividade das espécies. Portanto, esses aspectos devem ser considerados nos estudos que abordam as florestas ribeirinhas, bem como para a fundamentação de propostas de manejo e recuperação dessas áreas degradadas.

Agradecimentos - Os autores agradecem a todos os que colaboraram nos trabalhos de campo: Jeferson Lourenço, Fernando Nishio, Michel Metran Silva e Fábio F. Marqueti. Ao Aloysio de P. Teixeira e assessores anônimos pelas revisões críticas do manuscrito e aos taxonomistas Marcos Sobral (Myrtaceae), Roseli Torres (Salicaceae) e Jorge Tamashiro, pela ajuda na identificação de algumas espécies. Ao Conselho Nacional de Desenvolvimento Científico e Tecnológico (CNPq), pela concessão de bolsa de Iniciação Científica para o primeiro autor.

\section{Referências bibliográficas}

AB'SABER, A.N. 2000. O suporte geoecológico das florestas beiradeiras (ciliares). In Matas ciliares: conservação e recuperação. (R.R. Rodrigues \& H.F. Leitão Filho, eds.). Edusp, São Paulo, p.15-25.

APG II. 2003. An update of the Angiosperm Phylogeny Group classification for the orders and families of flowering plants: APG II. Botanical Journal of Linnean Society 141:399-436.

ASSAD-LUDEWIGS, I.Y., PINTO, M.M., SILVA FILHO, N.L., GOMES, E.D. \& KANASHIRO, S. 1989. Propagação, crescimento e aspectos ecofisiológicos em Croton urucurana Baill. (Euphorbiaceae), arbórea nativa pioneira de mata ciliar. In Anais do Simpósio Sobre Mata Ciliar. (L.M. Barbosa, coord.). Fundação Cargill, Campinas, p.284-298.

BERNACCI, L.C., GOLDEMBERG, R. \& METZGER, J.P. 1998. Estrutura florística de 15 fragmentos florestais ripários da bacia do Jacaré-Pepira (SP). Naturalia 23: 23-54.

BROKAW, N.V.L. 1982. The definition of treefall gap and its effect on measures of forest dynamics. Biotropica 14:158-159. 
BROWER, J.E. \& ZAR, J.H. 1984. Field and laboratory methods for general ecology. Wm. C. Brown Publishers, Dubuque.

BUDKE, J.C., JARENKOW, J.A. \& OLIVEIRA FILHO, A.T. 2008. Tree community features of two stands of riverine forest under different flooding regimes in Southern Brazil. Flora 203:162-174.

CAPON, S.J. \& BROCK, M.A. 2006. Flooding, soil seed bank dynamics and vegetation resilience of a hydrologically variable desert floodplain. Freshwater Biology 51: 206-223.

CATTANIO, J.H., ANDERSON, A.B. \& CARVALHO, M.S. 2002. Floristic composition and topographic variations in a tidal flood-plain forest in the Amazon estuary. Revista Brasileira de Botânica 25:419-430.

DAMASCENO JUNIOR, G.A., SEMIR, J., SANTOS, F.A.M. \& LEITÃO FILHO, H.F. 2005. Structure, distribution of species and inundation in a riparian forest of Rio Paraguai, Pantanal, Brazil. Flora 200: 119-135.

DENSLOW, J.S. 1980. Partitioning among tropical rainforest trees. Biotropica 12(supplement):47-55.

DURIGAN, G., RODRIGUES, R.R. \& SCHIAVINI, I. 2000. A heterogeneidade ambiental definindo a metodologia de amostragem da floresta ciliar. In Matas ciliares: conservação e recuperação. (R.R. Rodrigues \& H.F. Leitão Filho, eds.). Edusp, São Paulo, p.159-167.

FERREIRA, J.N. \& RIBEIRO, J.F. 2001. Ecologia da inundação em matas de galeria. In Cerrado: caracterização e recuperação de matas de galeria. (J.F. Ribeiro, C.E.J. Fonseca \& J.C. Souza Silva, eds.). Embrapa Cerrados, Planaltina, p.425-451.

GANDOLFI, S., LEITÃO FILHO, H.F. \& BEZERRA, C.L. 1995. Levantamento florístico e caráter sucessional das espécies arbustivo-arbóreas de uma floresta mesófila semidecídua no Município de Guarulhos, SP. Revista Brasileira de Biologia 55: 753-767.

GANDOLFI, S., JOLY, C.A. \& RODRIGUES, R.R. 2007. Permeability x impermeability: canopy trees as biodiversity filters. Scientia Agricola 64:433-438.

GIBBS, P.E. \& LEITÃO FILHO, H.F. 1978. Floristic composition of an area of gallery forest near Mogi Guaçu, state of São Paulo, S.E. Brazil. Revista Brasileira de Botânica 1:151-156.

GUARIGUATA, M.R. \& OSTERTAG, R. 2002. Sucessión secundária. In Ecología y conservación de bosques neotropicales (M.R. Guariguata \& G.H. Kattan, eds.). Ediciones LUR, Cartago, p.591-624.

IVANAUSKAS, N.M., RODRIGUES, R.R. \& NAVE, A.G. 1997. Aspectos ecológicos de um trecho de floresta de brejo em Itatinga, SP: florística, fitossociologia e seletividade de espécies. Revista Brasileira de Botânica 20:139-153.
JOLY, C.A. 1986. Heterogeneidade ambiental e diversidade de estratégias adaptativas de espécies arbóreas de mata de galeria. In Anais do X Simpósio Anual da Academia de Ciências do Estado de São Paulo. Perspectivas de Ecologia Teórica. Aciesp, São Paulo, v.2, p.19-38.

KOLB, R.M., MEDRI, M.E., BIANCHINI, E., PIMENTA, J.A., GILONI, P.C. \& CORREA, G.T. 1998. Anatomia ecológica de Sebastiania commersoniana (Baillon) Smith \& Downs (Euphorbiaceae) submetida ao alagamento. Revista Brasileira de Botânica 21:305-312.

KÖPPEN, W. 1948. Climatologia: con un estudio de los climas de la Tierra. Fondo de Cultura Economica, México.

LEMMON, P.E. 1957. A new instrument for measuring forest overstorey density. Journal of Forestry 55:67-668.

LOBO, P.C. \& JOLY, C.A. 2000. Aspectos ecofisiológicos da vegetação de mata ciliar do Sudeste do Brasil. In Matas ciliares: conservação e recuperação. (R.R. Rodrigues \& H.F. Leitão Filho, eds.). Edusp, São Paulo, p.143-157.

MAZZONI-VIVEIROS, S.C. \& LUCHI, A.E. 1989. Adaptações anatômicas. In Anais do Simpósio Sobre Mata Ciliar. (L.M. Barbosa, coord.). Fundação Cargill, Campinas, p.71-87.

MCCUNE, B. \& GRACE, J.B. 2002. Analysis of ecological communities. Glaneden Beach, Oregon.

MCCUNE, B. \& MEFFORD, M.J. 1999. PC-ORD. Multivariate analysis of ecological data, version 4.0 MjM Software Desing. Glaneden Beach, Oregon.

MILARÉ, E. 1991. Legislação ambiental no Brasil. Edições APMP, São Paulo.

MÜLLER-DOMBOIS, D. \& ELLENBERG, H. 1974. Aims and methods of vegetation ecology. John Wiley, New York.

OLIVEIRA FILHO, A.T., VILLELA, E.A., CARVALHO, D.A. \& GAVILANES, M.L. 1994. Differentiation of streamside and upland vegetation in an area of montane semideciduous forest in southeastern Brazil. Flora 189:287-305.

PIRES, A.S. 2003. Caracterização ambiental utilizando um sistema de informação geográfica, como subsídio ao planejamento de uma unidade de uso sustentável: Floresta Estadual Edmundo Navarro de Andrade em Rio Claro (SP), Brasil. Dissertação de mestrado, Universidade Estadual Paulista Júlio de Mesquita Filho, Rio Claro.

RODRIGUES, R.R. 2000. Uma discussão nomenclatural das formações ribeirinhas. In Matas ciliares: conservação e recuperação. (R.R. Rodrigues \& H.F. Leitão Filho, eds.). Edusp, São Paulo, p.91-100.

RODRIGUES, R.R. \& NAVE, A.G. 2000. Heterogeneidade florística das matas ciliares. In Matas ciliares: conservação e recuperação. (R.R. Rodrigues \& H.F. Leitão Filho, eds.). Edusp, São Paulo, p.45-71.

SHEPERD, G.J. 1995. FITOPAC 1. Manual do usuário. Departamento de Botânica. Universidade Estadual de Campinas, Campinas. 
SILVA, A.N., VAN DEN BERG, E. \& OLIVEIRA FILHO, A.T. 2007. Comparação florística de florestas inundáveis das regiões Sudeste e Sul do Brasil. Revista Brasileira de Botânica 30:257-269.

SOUZA, M.O.L. 2000. Evolução tectônica dos altos estruturais de Pitanga, Ártemis, Pau D’alho e Jibóia - Centro do Estado de São Paulo. Tese de doutorado, Universidade Estadual Paulista Júlio de Mesquita Filho, Rio Claro.

SOUZA, V.C. \& LORENZI, H. 2005. Botânica sistemática - Guia ilustrado para identificação das famílias de angiospermas da flora brasileira, baseado em APG II. Instituto Plantarum, Nova Odessa.

SOUZA, A.F. \& MARTINS, F.R. 2005. Spatial variation and dynamics of flooding, canopy openess, and structure in a Neotropical swamp forest. Plant Ecology 180: 161-173.
SOUZA, J.S., ESPÍRITO SANTO, F.D.B., FONTES, M.A.L., OLIVEIRA FILHO, A.T. \& BOTEZELLI, L. 2003. Análise das variações florísticas e estruturais da comunidade arbórea de um fragmento de floresta semidecídua às margens do rio Capivari, Lavras-MG. Revista Árvore 27:185-206.

TEIXEIRA, A.P., ASSIS, M.A., SIQUEIRA, F.R. \& CASAGRANDE, J.C. 2008. Tree species composition and environmental relationships in a Neotropical swamp forest in Southeastern Brazil. Wetlands Ecology and Management 16:451-461.

VAN DEN BERG, E. \& OLIVEIRA FILHO, A.T. 2000. Composição florística e fitossociológica de uma floresta ripária em Itutinga, MG, e comparação com outras áreas. Revista Brasileira de Botânica 23:231-253.

WHITMORE, T.C. 1989. Canopy gaps and the two major groups of forest trees. Ecology 70:536-538. 